\title{
Encapsulamento, crioproteção e desidratação na capacidade regenerativa de ápices caulinares de Genipa americana
}

\author{
Encapsulation, dehydration and cryoprotection in regenerative capacity \\ of shoot apices of Genipa americana
}

\author{
Francielen Paola de SáI Fernanda Vidigal Duarte Souza ${ }^{\text {II }}$ \\ Ana Veruska Cruz da Silva ${ }^{\text {III }}$ Ana da Silva Lédo ${ }^{\text {III* }}$
}

RESUMO

Genipa americana (jenipapeiro) é uma essência florestal pertencente à família Rubiaceae, que apresenta importância econômica e ambiental, sendo valorizada para produção de alimentos, na recuperação de áreas degradadas, na composição em áreas de preservação permanentes e em sistemas agroflorestais. Objetivou-se avaliar o efeito de diferentes tempos de desidratação em câmara de fluxo laminar e tempos de imersão em solução crioprotetora ( $M S+0,5 M$ de sacarose) na capacidade regenerativa de ápices caulinares da espécie para estabelecimento de futuros protocolos de criopreservação. Os ápices caulinares foram obtidos de plântulas, acesso Oiteiros, germinadas e cultivadas in vitro. Os explantes foram submetidos ao encapsulamento e a diferentes tempos de imersão em solução crioprotetora e tempos de desidratação em câmara de fluxo laminar. A crioproteção e a desidratação não alteram a viabilidade dos ápices caulinares de jenipapeiro encapsulados ou não encapsulados. A imersão por 24 horas em solução crioprotetora e a desidratação em câmara de fluxo laminar por 2 horas apresentam potencial para uso em futuros trabalhos de criopreservação por encapsulamentodesidratação.

Palavras-chave: jenipapeiro, Genipa americana, Conservação ex situ, Crioprotetor.

\section{ABSTRACT}

Genipa americana (genipap) is a forest species belonging to the Rubiaceae family that has economic and environmental importance, being valued for food production, recuperation of degraded areas, in the composition in areas of permanent preservation and agroforestry. The objective of this research was to evaluate the effect of different times of dehydration in laminar flow cab and immersion time in cryoprotecting solution $(M S+0.5 M$ sucrose $)$ on the regenerative capacity of shoot apices for establishing future cryopreservation protocols. The shoot apices were obtained from seedlings, of Oiteiros accession, germinated and cultured in vitro. Explants were subjected to encapsulation and different exposure times in cryoprotecting solution and dehydration in a laminar flow cab. The cryoprotection and dehydration does not modify the viability of the shoot apices of genipap encapsulated or unencapsulated. Immersion for 24 hours in cryoprotecting solution and the dehydration in a laminar flow cab by 2 hours have potential for use in future studies of cryopreservation by encapsulation-dehydration.

Key words: genipap, Genipa americana, Conservation ex situ, Cryoprotectant.

\section{INTRODUÇÃO}

Genipa americana (jenipapeiro) é uma espécie florestal, pertencente à família Rubiaceae, originária da América do Sul e Central. Apresenta relevância socioeconômica, podendo ser cultivada para fins madeireiros ou alimentícios, e importância ambiental, devido ao seu potencial para recuperação de áreas degradas e composição de áreas de preservação permanente (LORENZI, 1992; SALOMÃO \& PADILHA, 2006).

A espécie foi selecionada entre as dez de altíssima prioridade pelo programa Plantas do Futuro do CNPq/Banco Mundial/ Global Environment Facility/Ministério do Meio Ambiente (MMA)/Probio coordenado pelo MMA,

\footnotetext{
'Programa de Pós-graduação em Biotecnologia de Recursos Naturais, Universidade Federal de Sergipe (UFS), Jardim Rosa Elze, São Cristóvão, SE, Brasil.

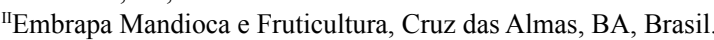

IIIEmbrapa Tabuleiros Costeiros, CP 44, 49025-040, Aracaju, SE, Brasil. E-mail: ana.ledo@embrapa.br. *Autor para correspondência. Recebido 16.04.14 Aprovado 26.02.15 Devolvido pelo autor 10.08.15 CR-2014-0579.R
} 
com maior potencial de uso imediato entre as fruteiras nativas (FERREIRA et al., 2005).

Esta espécie é classificada como intermediária, ou seja, suas sementes toleram a dessecação entre 7 e 10\% de teor de água e não suportam baixas temperaturas durante períodos prolongados, perdendo a viabilidade em até 60 dias (FERREIRA et al., 2007; OLIVEIRA et al., 2011). Diante disso, a sua conservação via banco de sementes não é indicada, sendo as coleções de campo a estratégia mais utilizada. O diretório de coleções de germoplasma da América Latina e Caribe registra a conservação a campo de 11 acessos dispersos em nove instituições da América Latina (SILVA et al., 2006).

Nesse sentido, a aplicação de técnicas de cultura de tecidos de plantas como estratégia complementar à conservação da variabilidade genética existente e para acelerar a multiplicação de genótipos promissores torna-se imprescindível (PILATTI et al., 2011).

Diversas técnicas baseadas no crescimento lento ou na criopreservação têm sido empregadas para a conservação do material vegetal in vitro. O método de conservação por crescimento lento consiste na redução do metabolismo da planta através da manipulação do ambiente e das condições de cultivo, e o armazenamento do material ocorre somente a curtos ou médios prazos (ENGELMANN, 2011). A criopreservação é o armazenamento do material à temperatura ultrabaixa $\left(-196^{\circ} \mathrm{C}\right)$, geralmente em nitrogênio líquido. A exposição às temperaturas negativas paralisa todas as atividades, como divisão celular e reações metabólicas, permitindo o armazenamento do material vegetal por tempo indeterminado (ENGELMANN, 2004).

A redução de água dos eixos embrionários em um nível possível de submetê-lo à temperatura do nitrogênio líquido e/ou evitar a formação de cristais de gelo é o passo mais crítico na obtenção de um protocolo viável de criopreservação (LOPES et al., 2013). A desidratação pode ser obtida pela evaporação da água, promovida pela exposição do material à sílica gel ou câmara de fluxo laminar ou pelo uso de crioprotetores que provocam a desidratação osmótica do material (SANTOS, 2004). A desidratação pode provocar modificações deletérias afetando o metabolismo celular, havendo um intervalo de umidade aceitável a ser atingido pelos explantes antes do congelamento, porém, a remoção da umidade abaixo de limite tolerável afeta diretamente a estrutura molecular e a integridade das organelas (SILVA et al., 2011; SERSHEN et al.,
2012), o que se reflete em menor regeneração após a etapa do descongelamento.

O objetivo deste trabalho foi avaliar o efeito de diferentes tempos de desidratação em câmara de fluxo laminar e tempos de imersão em solução crioprotetora na capacidade regenerativa de ápices caulinares de Genipa americana, para estabelecimento de futuros protocolos de criopreservação.

\section{MATERIAL E MÉTODOS}

Foram utilizadas como fonte de explantes plântulas obtidas da germinação in vitro de sementes da planta matriz do acesso Oiteiros, coletadas no povoado de Oiteiros, Nossa Senhora do Socorro, SE (9॰40'52.10”'S; 3705'12.45”O).

Das plântulas germinadas in vitro, foram excisados segmentos nodais com aproximadamente $2 \mathrm{~cm}$ e inoculados em frascos de vidro com capacidade de $250 \mathrm{~mL}$, contendo $30 \mathrm{~mL}$ de meio de cultura Murashige \& Skoog - MS (MURASHIGE \& SKOOG, 1962), suplementado com $30 \mathrm{~g} \mathrm{~L}^{-1}$ de sacarose; $1 \mathrm{mg} \mathrm{L}^{-1}$ de BAP e 4,5g L-1 de Phytagel $^{\circledR}$ (meio de regeneração, ROCHA et al., 2008), com pH ajustado para $5,8 \pm 1$ e autoclavado por 20 minutos a $121 \pm 1^{\circ} \mathrm{C}$ e pressão de $1,05 \mathrm{~atm}$. As culturas foram mantidas em sala de crescimento com temperatura controlada de $25 \pm 2^{\circ} \mathrm{C}$, umidade relativa do ar média em torno de $70 \%$, fotoperíodo de 12 horas de luz e intensidade luminosa de $60 \mu \mathrm{mol} \mathrm{m} \mathrm{m}^{-2} \mathrm{~s}^{-1}$.

Após quatro meses de cultivo, a partir das brotações adventícias emitidas, foram excisados 176 ápices caulinares de aproximadamente $5 \mathrm{~mm}$ de comprimento. A fim de verificar a capacidade regenerativa dos explantes, cerca de 10 ápices caulinares foram diretamente inoculados em frascos de vidro, com capacidade de $250 \mathrm{~mL}$ contendo $30 \mathrm{~mL}$ de meio de cultura de regeneração (Controle 1). Os demais ápices (166) foram imersos, aproximadamente por 5 minutos, em 100mL do meio de cultura MS (sem $\mathrm{Ca}^{+2}$ ) acrescido da solução de alginato de sódio $3 \%$ $(\mathrm{m} / \mathrm{v})$ Sigma-Aldrich A20-33, conforme metodologia de SOLIMAN et al. (2013). Em seguida, com auxílio da pipeta de Pasteur, foram aspirados e depositados na solução de $100 \mathrm{mM}$ de cloreto de cálcio $\left(\mathrm{CaCl}_{2}\right)$, Sigma-Aldrich $\mathrm{C} 10-16$, por 20 minutos, sob agitação, para polimerização das cápsulas contendo os explantes. A fim de verificar possíveis efeitos do encapsulamento na regeneração, 10 cápsulas contendo ápices caulinares foram imediatamente inoculadas no meio de regeneração (Controle 2) e 12 utilizadas para determinação da umidade inicial. 
Os explantes encapsulados restantes (144) foram transferidos para solução crioprotetora composta por meio MS suplementado com $0,5 \mathrm{M}$ de sacarose (SOLIMAN, 2013 adaptado) sob agitação a 100rpm (SHARAF et al., 2012) onde permaneceram por 24 e 48 horas a $25 \pm 2^{\circ} \mathrm{C}$ na ausência de luz.

Para desidratação em câmara de fluxo laminar, as cápsulas foram colocadas em placas de Petri sobre papel filtro para retirada do excesso do meio de cultura e mantidas em diferentes tempos de exposição ao fluxo de ar: 0,2 e 4 horas, em temperatura ambiente $\left(25 \pm 2^{\circ} \mathrm{C}\right)$.

Após o encapsulamento e os procedimentos de crioproteção e desidratação, 72 cápsulas foram inoculadas em frascos de vidro com capacidade de $250 \mathrm{~mL}$, contendo $30 \mathrm{~mL}$ de meio de cultura de regeneração, e mantidos em sala de crescimento nas condições descritas anteriormente.

Para a determinação da umidade, foram utilizadas 72 cápsulas contendo os ápices caulinares. Após o encapsulamento, foram pesadas para determinar o peso da massa fresca (MF) e, depois de cada período de imersão em solução crioprotetora ( 24 e 48 horas) e de desidratação em câmara de fluxo laminar (0, 2 e 4 horas), foram colocadas em estufa a $90^{\circ} \mathrm{C}$ por 16 horas (SHARAF et al., 2012) e pesadas para determinação da massa seca (MS). A umidade (U) foi determinada pela seguinte fórmula $U=(M F-$ $\mathrm{MS}) / \mathrm{MF}^{*} 100$.

Após três meses de cultivo in vitro, as culturas foram avaliadas quanto à porcentagem de regeneração, número de brotações adventícias emitidas por ápice caulinar, número de folhas formadas por ápice caulinar, comprimento médio das brotações adventícias $(\mathrm{cm})$ e porcentagem de explantes com calos.

O experimento foi instalado em delineamento inteiramente casualizado em esquema fatorial 2x3 (dois tempos de imersão em solução crioprotetora $\mathrm{x}$ três tempos de desidratação), com quatro repetições. Cada parcela foi composta por três ápices caulinares encapsulados, totalizando 144 cápsulas. Os dados foram submetidos à análise de variância e comparadas pelo teste de Tukey a 5\% de significância, utilizando o programa estatístico SISVAR (FERREIRA, 2011).

\section{RESULTADOS E DISCUSSÃO}

Houve efeito significativo dos tempos de imersão na solução crioprotetora (meio MS completo $+0,5 \mathrm{M}$ de sacarose) e tempos de desidratação em câmara de fluxo laminar nas umidades dos ápices caulinares. A imersão por 24 e 48 horas na solução crioprotetora promoveu redução da umidade, 23,31 e $28,47 \%$, respectivamente, em relação à umidade inicial das cápsulas $(66,68 \%)$ (Figura 1A). Ápices caulinares encapsulados e não desidratados, independente do tempo de imersão na solução crioprotetora, apresentaram maior umidade (47,96\%) (Figura 1B). A exposição ao fluxo de ar por 2 e 4 horas foi efetiva na redução da umidade para $22,47 \%$ e $7,23 \%$, respectivamente. SOLIMAN (2013), trabalhando com gemas apicais de Prunus armeniaca, verificou que as cápsulas não desidratadas em câmara de fluxo laminar obtiveram $76,55 \%$ de umidade e, após o cultivo em solução de sacarose e desidratação por 4 horas em câmara de fluxo laminar, houve redução para 46,12\%. Em estudos conduzidos com gemas apicais encapsuladas de Hancornia speciosa, SARTOR et al. (2012) também não obtiveram significativa redução da umidade após 3 horas de desidratação em câmara de fluxo laminar (49,55\%). LOPES (2005) obteve uma redução de em torno de $69 \%$ da umidade de ápices caulinares de Gossypium hirsutum L. encapsulados e cultivados por 24 horas em solução crioprotetora com $0,3 \mathrm{M}$ de sacarose e desidratadas por 9 horas em câmara de fluxo laminar. Observa-se uma variação na umidade de diferentes espécies em função do tempo de crioproteção e desidratação.

Não houve efeito significativo do tempo de imersão em solução crioprotetora e do tempo de desidratação e interação dos fatores para a porcentagem de regeneração. Em todos os tratamentos, foram alcançados valores altos de regeneração acima de $75 \%$, sendo, no tempo de desidratação de duas horas, observado $100 \%$ de regeneração (Tabela 1).

Não houve efeito significativo do tempo de imersão em solução crioprotetora para o número de brotações adventícias por ápice caulinar, comprimento da maior brotação adventícia e número de folhas. Observou-se que as cápsulas submetidas à crioproteção por 24 horas apresentaram as seguintes médias para essas variáveis 2,$70 ; 16,18$ e $2,43 \mathrm{~cm}$, e por 48 horas 2,$41 ; 14$ e $1,98 \mathrm{~cm}$, respectivamente.

Houve efeito significativo dos tempos de desidratação em câmara de fluxo laminar para o número de brotações adventícias por ápice caulinar, comprimento da maior brotação e número de folhas. Ápices caulinares encapsulados e desidratados por duas horas e não desidratados apresentaram as maiores médias de número de brotações adventícias (3,5 e 2,6, respectivamente), quando comparado com a 


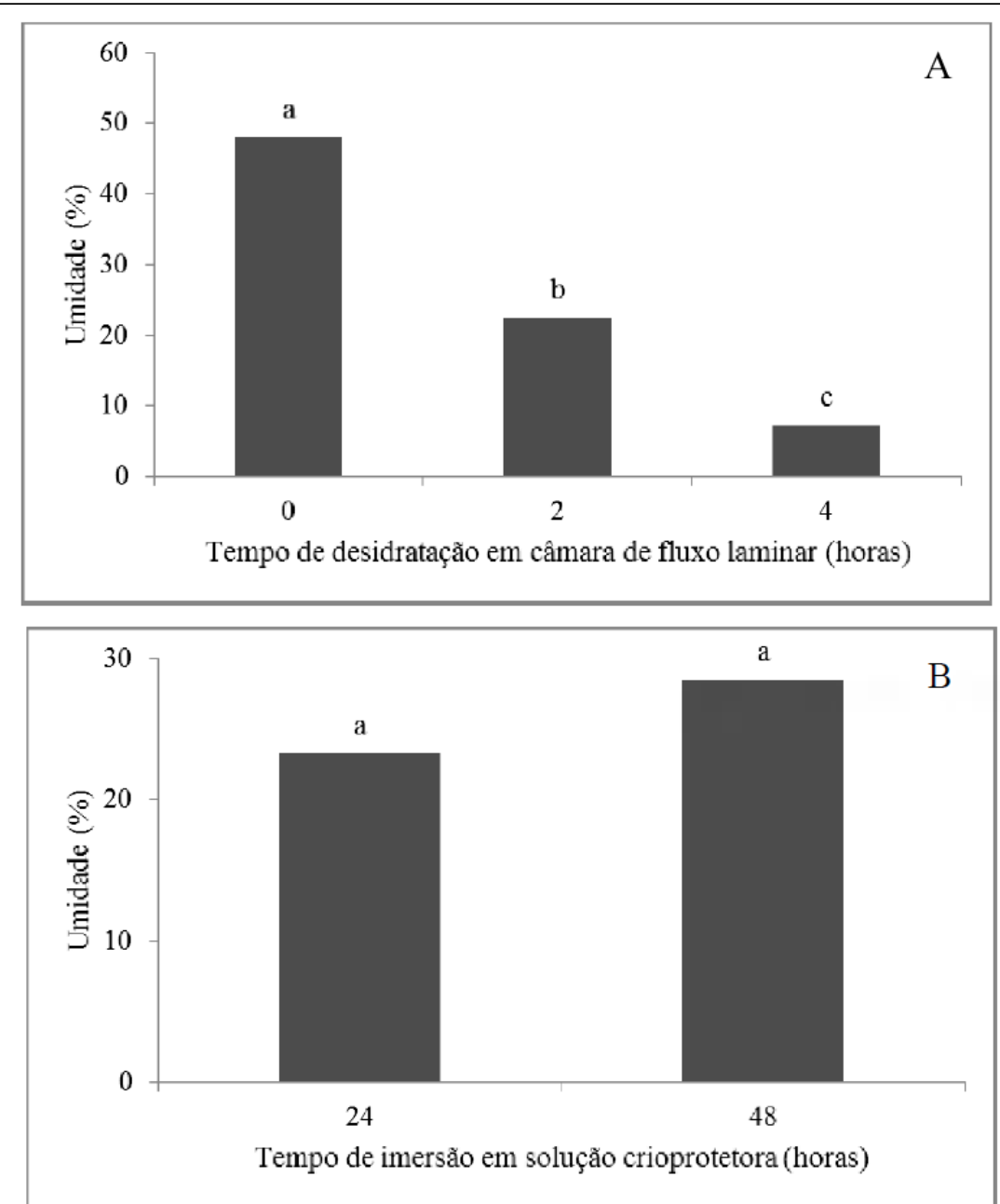

Figura 1 - Umidade média dos ápices caulinares encapsulados de Genipa americana, submetidos a: A- três tempos de desidratação em câmara de fluxo laminar; Bdois tempos imersão em solução crioprotetora $\mathrm{MS}+0,5 \mathrm{M}$ de sacarose. Médias seguidas pela mesma letra não diferem entre si pelo teste de Tukey a $5 \%$ de probabilidade.

desidratação por 4 horas (Figura 2A). O maior tempo de exposição na câmara de fluxo laminar resultou em menor número de brotações emitidas $(1,54)$, possivelmente, devido ao efeito negativo da baixa umidade das cápsulas promovido por esse tratamento. De acordo com SANTOS (2013), a desidratação pode provocar modificações deletérias, afetando o metabolismo celular. Há um intervalo de umidade aceitável a ser atingido pelos explantes antes do congelamento, porém, a remoção da umidade abaixo de limite tolerável afeta diretamente a estrutura molecular e a integridade das organelas (SILVA et al., 2011; SERSHEN et al., 2012), o que se reflete em menor regeneração.

$$
\text { Ápices caulinares encapsulados }
$$

desidratados por duas horas e não desidratados apresentaram o maior número de folhas (19 e 16,30 , respectivamente) quando comparados com cápsulas desidratadas por quatro horas (10) (Figura 2B). Quanto ao comprimento da maior brotação adventícia, ápices caulinares encapsulados e desidratados por até duas horas e não desidratados apresentaram maiores médias $(2,60$ e $2,43 \mathrm{~cm}$, 
Tabela 1 - Porcentagem de regeneração e de presença de calo em ápices caulinares encapsulados de Genipa americana em função do tempo de desidratação em câmara de fluxo laminar e do tempo de imersão em solução crioprotetora MS+0,5M de sacarose.

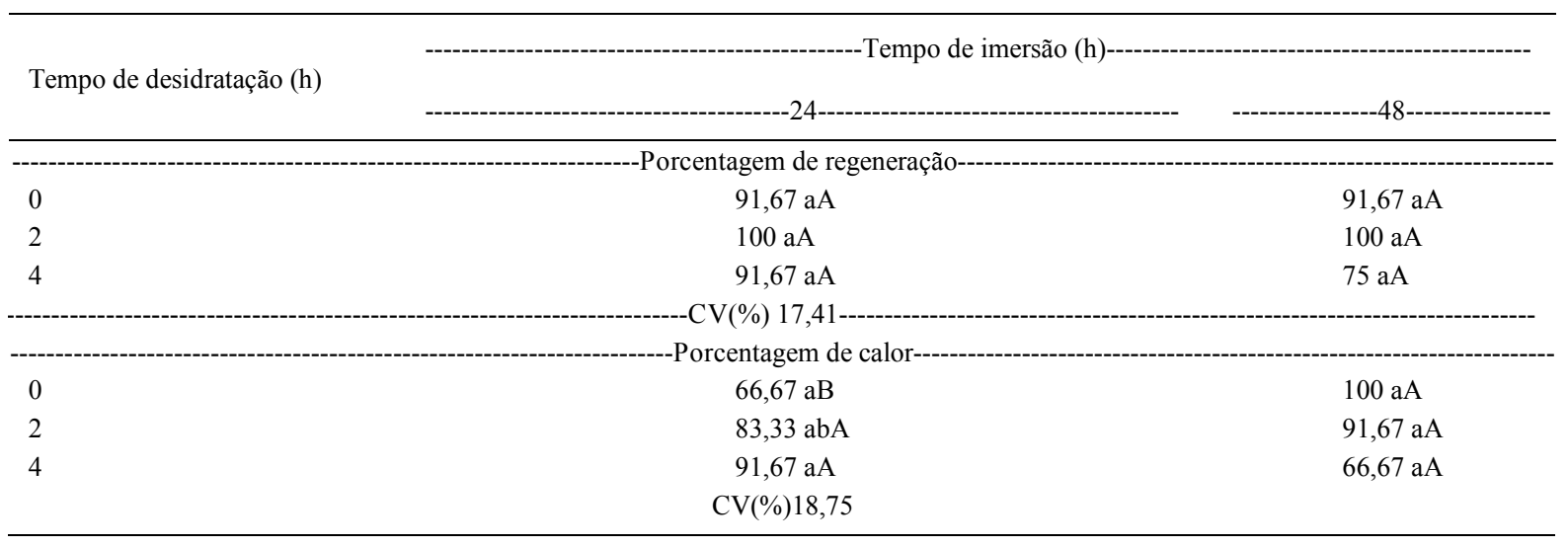

Médias seguidas pela mesma letra minúsculas na linha e maiúscula na coluna não diferem entre si pelo teste de Tukey a $5 \%$ de probabilidade.

respectivamente), conforme a figura 2C. A exposição das cápsulas com ápices à desidratação por quatro horas na câmara de fluxo laminar reduziu o crescimento $(1,57 \mathrm{~cm})$, provavelmente, devido à menor umidade e a intolerância dos explantes à dessecação. Resultado semelhante foi obtido por LOPES (2005), que verificou a redução do comprimento de brotos emitidos por nós cotiledonares encapsulados de Gossypium hirsutum com o aumento do tempo de permanência em câmara de fluxo laminar.

A exposição no fluxo laminar por quatro horas promoveu uma alta redução da umidade das cápsulas em 59,45\% e menor desempenho em crescimento na regeneração. Este resultado concorda com os relatos de SILVA et al. (2011) e SERSHEN et al. (2012) de que a remoção da umidade abaixo de limite tolerável afeta diretamente a estrutura molecular e a integridade das organelas, o que se reflete em menor regeneração após a etapa do descongelamento.

Houve interação significativa entre tempo de imersão na solução crioprotetora e o tempo de desidratação para a porcentagem de explantes com calos. Todos os ápices caulinares encapsulados, imersos por 48 horas na solução crioprotetora e não desidratados, apresentaram calo na base dos explantes (100\%) (Tabela 1). Os explantes imersos por 24 horas em solução crioprotetora e não desidratados em câmara de fluxo laminar e os imersos por 48 horas e desidratados por quatro horas apresentaram menor percentual de calogênese $(66,67 \%)$.

Possivelmente, a formação de calos não seja um efeito direto da exposição à solução crioprotetora, considerando que foi observada a calogênese em ápices caulinares e ápices caulinares encapsulados inoculados no meio de regeneração (controles 1 e 2). Provavelmente, essa resposta foi ocasionada pela presença da citocinina 6-benzilaminopurina (BAP) no meio de regeneração, fato esse também observado por ROCHA et al. (2008) em G. americana.

A formação intermediária de calos durante a regeneração dos explantes aumenta a possibilidade de variação somaclonal, evento que deve ser minimizado em protocolos de conservação de germoplasma em longo prazo (SANTOS, 2004).

\section{CONCLUSÃO}

A imersão em solução crioprotetora (MS+0,5M de sacarose) e a desidratação em câmara de fluxo laminar não altera a viabilidade dos ápices caulinares de Genipa americana L., encapsulados ou não encapsulados, e reduzem a umidade.

A imersão por 24 horas em solução crioprotetora (MS+0,5M de sacarose) e a desidratação por duas horas em câmara de fluxo laminar apresentam potencial para uso em futuros trabalhos de criopreservação por encapsulamentodesidratação. 

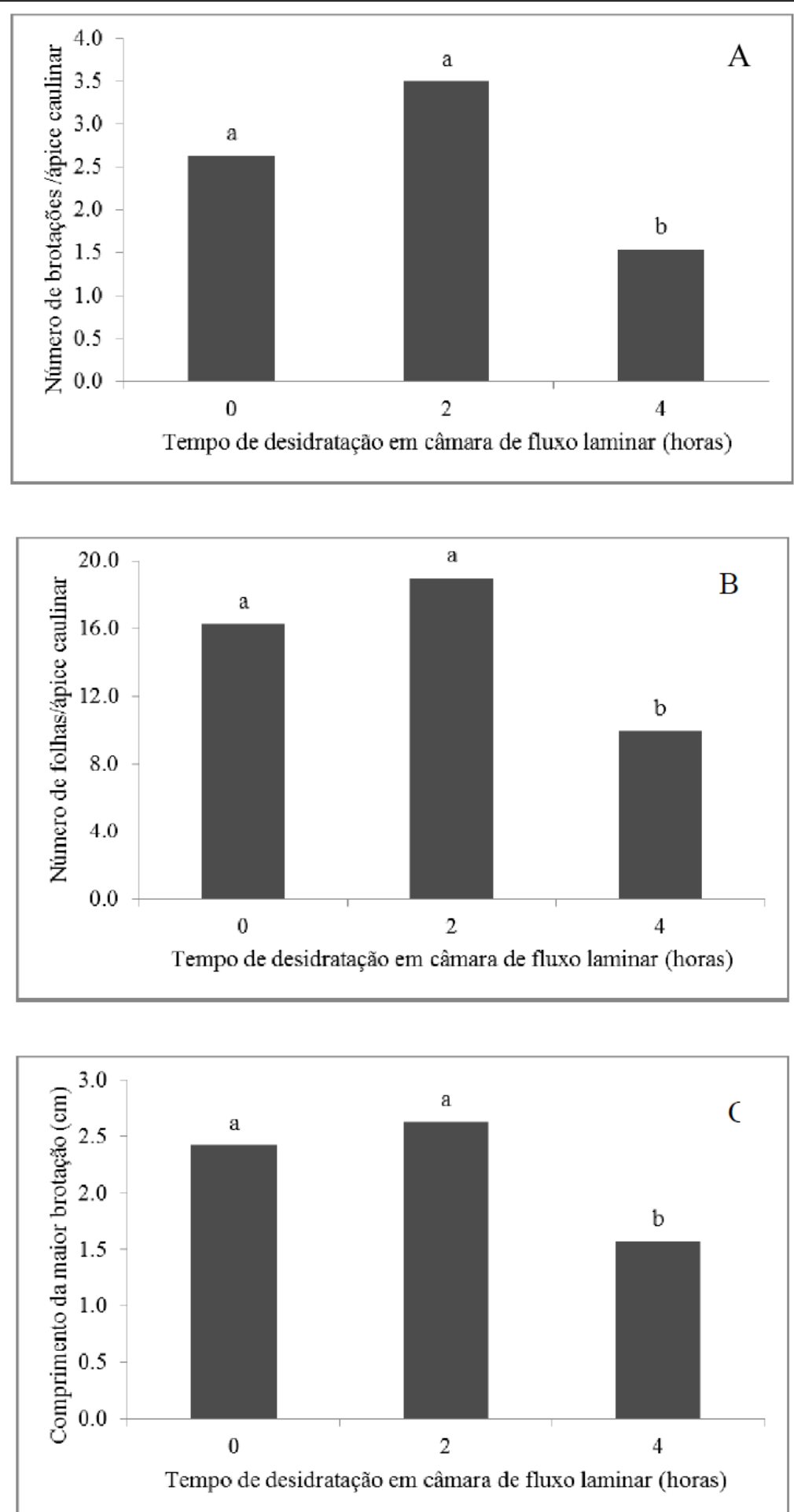

Figura 2 - A: Número de brotações adventícias por ápice caulinar, B: número de folhas emitidas por ápice caulinar e C: comprimento médio das brotações po ápice caulinar encapsulado de Genipa americana, em função do tempo de desidratação em câmara de fluxo laminar. Médias seguidas pela mesma letra não diferem entre si pelo teste de Tukey a $5 \%$ de probabilidade. 


\section{AGRADECIMENTOS}

Ao Programa Nacional de Cooperação Acadêmica da Coordenação de Aperfeiçoamento de Pessoal de Nível Superior (CAPES), pela concessão de bolsa, à Fundação de Apoio à Pesquisa e à Inovação Tecnológica do Estado de Sergipe (FAPITEC/SE) e à Embrapa Tabuleiros Costeiros, pelo aporte de recursos financeiros e estrutura.

\section{REFERÊNCIAS}

ENGELMANN, F. Plant cryopreservation: progress and prospects. In vitro Cell \& Developmental Biology-Plant, v.40, n.5, p.427-433, 2004. Disponível em: <http://link.springer.com/ article/10.1079/IVP2004541\#page-1>. Acesso em: 28 nov. 2014

ENGELMANN, F. Use of biotechnologies for the conservation of plant biodiversity. In vitro Cell \& Developmental BiologyPlant, v.47, n.5, p.5-16, 2011. Disponível em: <http://link. springer.com/article/10.1007/s11627-010-9327-2\#page-1>. Acesso em: 28 nov. 2014

FERREIRA, D.F. Sisvar: a computer statistical analysis system. Ciência e Agrotecnologia, v.35, n.6, p.1039-1042, 2011. Disponível em: <http://www.scielo.br/scielo.php?pid=S1413$70542011000600001 \&$ script $=$ sci arttext $>$. Acesso em: 15 out. 2013. doi: $10.1590 / \mathrm{S} 1413-7054 \overline{2} 011000600001$

FERREIRA, E.G. et al. Frutíferas. In: SAMPAIO, E.V.S.B. et al. (Org.). Espécies da flora nordestina de importância econômica potencial. Recife: Associação Plantas do Nordeste, 2005. p.49-100.

FERREIRA, W.R. et al. Crescimento de mudas de Genipa americana L. submetidas a condições de pré-semeadura. Revista Brasileira de Biociências, v.5, p.1026-1028, 2007. Disponível em: $\quad<$ http://www.ufrgs.br/seerbio/ojs/index.php/rbb/article/ viewFile/828/697>. Acesso em: 12 fev. 2013.

LOPES, K.P. Criopreservação de germoplasma de oleaginosas de importância econômica para o nordeste Brasileiro. 2005. 113f. (Tese em Agronomia) - Curso de Pós-graduação em Agronomia, Universidade Federal da Paraíba, PB.

LOPES, K.P. et al. Criopreservação de eixos embrionários zigóticos de algodoeiro. Revista Brasileira de Engenharia Agrícola e Ambiental, v.17, n.3, p.291-298, 2013.

LORENZI, H. Árvores brasileiras: manual de identificação e cultivo de plantas arbóreas nativas do Brasil. Nova Odessa: Plantarum, 1992. 368p.

MURASHIGE, T.; SKOOG, F. A revised medium for rapid growth and bioassays with tobacco tissue culture. Physiologia Plantarum, v.15, p.437-497, 1962. Disponível em: <http://onlinelibrary. wiley.com/doi/10.1111/j.1399-3054.1962.tb08052.x/references>. Acesso em: 25 abr. 2013.

OLIVEIRA, L.M. et al. Períodos e ambientes de secagem na qualidade de sementes de Genipa americana L. Semina: Ciências Agrárias, v.2, p.495-502, 2011. Disponível em: <http://www.uel. br/revistas/uel/index.php/semagrarias/article/view/3521>. Acesso em: 28 fev. 2013. doi: 10.5433/1679-0359.
PILATTI, F.K. et al. In vitro and cryogenic preservation of plant biodiversity in Brazil. In Vitro Cellular Development Biology Plant, v.47, p.82-98, 2011. Disponível em: <http://link.springer. com/article/10.1007/s11627-010-9302-y>. Acesso em: 2 jan. 2014. doi: 10.1007/s11627-010-9302-y.

ROCHA, M.A.C. et al. Enraizamento in vitro e aclimatização de genótipos de jenipapeiro (Genipa americana L.). Revista Brasileira de Fruticultura, v.30, n.3, p.769-774, 2008. Disponível em: <http://www.scielo.br/scielo.php?pid=S0100$29452008000300035 \&$ script $=$ sci arttext $>$. Acesso em: 7 abr. 2014. doi: 10.1590/S0100-29452008000300035.

SALOMÃO, N.A.; PADILHA, L.S. Avaliação preliminar da germinabilidade e da microflora associada às sementes de Genipa americana em diferentes estágios de maturação. Brasília: Embrapa Recursos Genéticos e Biotecnologia, 2006. (Circular Técnica, 50).

SANTOS, I.R.I. Criopreservação de eixos embrionários de espécies de citrus usando o encapsulamento e desidratação. Brasília: Embrapa Recursos Genéticos e Biotecnologia, 2004. 24p. (Documentos, 115)

SANTOS, P.A.A. Cultivo e conservação in vitro de Hancornia speciosa Gomes. 2013. 94f. (Tese em Fisiologia Vegetal) - Curso de Pós-graduação em Fisiologia Vegetal, Universidade Federal de Lavras, MG.

SARTOR, F.R. et al. Técnicas para criopreservação de gemas de mangabeira. Revista Agrotecnologia, v.3, n.1, p.31-39, 2012.

SHARAF, S.A. et al. Cryopreservation of wild Shih (Artemisia herba-alba Asso.) shoot-tips by encapsulation-dehydration and encapsulation-vitrification. Plant Cell Tissue Organ Culture, v.108, p.437-444, 2012. Disponível em: <http://link.springer.com/ article/10.1007/s11240-011-0054-0>. Acesso em: 28 maio 2013. doi: $10.1007 / \mathrm{s} 11240-011-0054-0$.

SERSHEN, P.B. et al. Rate of dehydration, state of subcellular organization and nature of cryoprotection are critical factors contributing to the variable success of cryopreservation: studies on recalcitrant zygotic embryos of Haemanthus montanus. Protoplasma, v.249, p.171-186, 2012. Disponível em: <http:// www.ncbi.nlm.nih.gov/pubmed/21499854>. Acesso em: 27 set. 2013. doi: 10.1007/s00709-011-0275-4.

SILVA, R.C. et al. Potencial germinativo e morfoanatomia foliar de plântulas de pinhão-manso originadas de germoplasma criopreservado. Pesquisa Agropecuária Brasileira, v.46, n.8, p.836-844, 2011. Disponível em: <http://seer/sct/ embrapa.br/index.php/pab/article/view/9954/6507>. Acesso em: 15 jun. 2013.

SILVA, D.B. et al. Jenipapo. In: VIEIRA R.F. et al. Frutas nativas da região Centro Oeste do Brasil. Brasília: Embrapa Recursos Genéticos e Biotecnologia, 2006. p.304-322.

SOLIMAN, H.I.A. Cryopreservation of in vitro-grown shoot tips of apricot (Prunus armeniaca L.) using encapsulationdehydration. African Journal of Biotechnology, v.12, p.14191430, 2013. Disponível em: <http://academicjournals.org/article/ article13807294 Soliman.pdf $>$. Acesso em: 19 jun. 2013. doi: $10.5897 / \mathrm{AJB} 12 . \overline{2} 857$. 